\title{
Differentiation in the protein synthesis-dependency of persistent synaptic plasticity in mossy fiber and associational/commissural CA3 synapses in vivo
}

\author{
Hardy Hagena ${ }^{1,2}$ and Denise Manahan-Vaughan ${ }^{1,2 *}$ \\ ${ }^{1}$ Department of Neurophysiology, Medical Faculty, Ruhr University Bochum, Bochum, Germany \\ 2 International Graduate School for Neuroscience, Ruhr University Bochum, Bochum, Germany
}

Edited by:

Sidarta Ribeiro, Federal University of Rio Grande do Norte, Brazil

Reviewed by:

Marcos G. Frank, University of

Pennsylvania, USA

Richardson N. Leão, Brain Institute,

Brazil

Constantine Pavlides, The

Rockefeller University, USA

${ }^{*}$ Correspondence:

Denise Manahan-Vaughan,

Department of Neurophysiology,

Medical Faculty, Ruhr University

Bochum, Universitätsstr. 150,

MA 4/150, 44780 Bochum,

Germany.

e-mail:dmv-igsn@rub.de
Long-term potentiation (LTP) and long-term depression (LTD) are two mechanisms involved in the long-term storage of information in hippocampal synapses. In the hippocampal CA1 region, the late phases of LTP and LTD are protein-synthesis dependent. In the dentate gyrus, late-LTP but not LTD requires protein synthesis. The protein synthesis-dependency of persistent plasticity at CA3 synapses has not yet been characterized. Here, the roles of protein transcription and translation at mossy fiber (mf) and associational/commissural (AC)- synapses were studied in freely behaving rats. In control animals, low-frequency stimulation (LFS) evoked robust LTD ( $>24 \mathrm{~h}$ ), whereas high-frequency stimulation (HFS) elicited robust LTP ( $>24 \mathrm{~h}$ ) at both mf-CA3 and AC-CA3 synapses. Translation inhibitors prevented early and late phases of LTP and LTD at mf-CA3 synapses. In contrast, at AC-CA3 synapses, translation inhibitors prevented intermediate/late-LTP and late-LTD only. Transcription effects were also synapse-specific: whereas transcription inhibitors inhibited late-LTP and late-LTD ( $>3 \mathrm{~h})$ at $\mathrm{mf}-\mathrm{CA} 3$ synapses, at AC-CA3 synapses, protein transcription affected early-LTP and late-LTD. These results show that the AC-CA3 and mf-CA3 synapses display different properties in terms of their protein synthesis dependency, suggesting different roles in the processing of short- and long term synaptic plasticity.

Keywords: associational-commissural fibers, CA3, mossy fibers, protein-synthesis, transcription

\section{INTRODUCTION}

Many of the synaptic modifications that support persistent changes in synaptic strength require de novo protein synthesis. Protein synthesis, in turn, underlies many forms of long-term memory (Davis and Squire, 1984; Abraham and Williams, 2003; Sutton and Schuman, 2006). In the hippocampus, one of the most important structures for declarative memory formation, functional differentiation has been proposed for its neuroanatomically-defined subregions. Whereas the dentate gyrus is believed to engage in pattern separation (Treves and Rolls, 1992; O'Reilly and McClelland, 1994; Gilbert et al., 2001), the CA3 region may enable pattern completion (Marr, 1971; Nakazawa, 2002). CA1 may mediate error detection (Vinogradova, 2001; Lisman and Grace, 2005; Kumaran and Maguire, 2007) and the generation of an integrated spatial representation (Goodrich-Hunsaker et al., 2008). The main mechanisms underlying persistent synaptic information storage, and therefore perhaps memory, comprise long-term potentiation (LTP) and long-term depression (LTD). These forms of synaptic plasticity display different dependencies on protein translation and transcription, depending on the hippocampal subregion investigated (Krug et al., 1984; Frey et al., 1988; Huang et al., 1994; Nguyen et al., 1994). This may reflect functional differentiation of the roles LTP and LTD play in the generation of memory engrams. Indeed, it has been reported that expression of persistent LTP is associated with acquisition of knowledge about space, whereas LTD is associated with learning about spatial context (Kemp and Manahan-Vaughan, 2007, 2008; Hagena and Manahan-Vaughan, 2011).

The role of protein synthesis in these forms of long-lasting plasticity in the CA3 region of intact animals has not yet been explored. Whether persistent synaptic plasticity in CA3 depends on protein synthesis is an important question as the CA3 region is believed to play a unique role in memory formation. Neuroanatomically, the CA3 pyramidal cells receive input from mossy fibers that terminate on the proximal portion of dendrites (Blackstad and Kjaerheim, 1961; Amaral, 1979) and express an N-methyl-D-aspartate receptor (NMDAR)-independent form of LTP (Harris and Cotman, 1986; Zalutsky and Nicoll, 1990). Expression of this form of LTP depends on presynaptic mechanisms (Staubli et al., 1990; Xiang et al., 1994; Weisskopf and Nicoll, 1995). Furthermore, LTD that is elicited by low-frequency stimulation (LFS), is preceded by potent facilitation of synaptic responses (called frequency facilitation) that is not seen at other hippocampal synapses (Salin et al., 1996; Toth et al., 2000; Moore et al., 2003; Hagena and Manahan-Vaughan, 2010). The role of mossy fiber (mf) plasticity in memory is unknown-however, the unique properties of frequency facilitation suggest it may play a role in working memory and/or informational integration. CA3 pyramidal cells also receive input from associational 
fibers originating from CA3 cells of the ipsilateral hemisphere and from commissural fibers of the contralateral hemisphere (Blackstad, 1956; Ishizuka et al., 1990). These synapses display an NMDAR-dependent form of synaptic plasticity (Blackstad, 1956; Ishizuka et al., 1990; Debanne et al., 1998). The recurrent fibers of the commissural/associational CA3 projections to CA3 enable a very intense activation of the CA3 pyramidal cells that may play an intrinsic role in long-term memory formation (Marr, 1971; Treves and Rolls, 1994; Nakazawa, 2002; Kesner and Warthen, 2010; Hagena and Manahan-Vaughan, 2012).

This study set about to clarify if long-term synaptic plasticity $(>24 \mathrm{~h})$ at the $\mathrm{mf}-\mathrm{CA} 3$ and commissural/associational-CA3 synapse requires either protein translation or transcription. Our findings support that both LTP and LTD depend on protein transcription but their requirements for protein translation are temporally distinct. This difference is likely to support their functional differentiation with regard to information storage and memory formation.

\section{MATERIALS AND METHODS}

The present study was carried out in accordance with the European Communities Council Directive of September 22nd, $2010(2010 / 63 / \mathrm{EU})$ for care of laboratory animals and after approval of the local government ethics committee. All efforts were made to minimize the number of animals used.

\section{ELECTROPHYSIOLOGY}

Seven- to eight- week old male Wistar rats (Charles River, Germany) were anaesthetized (Pentobarbital, $52 \mathrm{mg} / \mathrm{kg}$, intraperitoneally) and underwent chronic implantation of hippocampal electrodes and a guide cannula, as described previously (Manahan-Vaughan, 1997; Hagena and ManahanVaughan, 2011), using coordinates based on the rat brain atlas from Paxinos and Watson (1986). Briefly, for mf-CA3 implantations, the recording electrode was placed above the CA3 pyramidal layer of the dorsal hippocampus, $3.2 \mathrm{~mm}$ posterior to bregma and $2.2 \mathrm{~mm}$ lateral to midline. The bipolar stimulation electrode was implanted $3.5 \mathrm{~mm}$ posterior to bregma and $2.0 \mathrm{~mm}$ lateral to midline (Figure 1). For commissural/associational (AC)- CA3 implantations, the recording electrode was placed $3.1 \mathrm{~mm}$ posterior tor bregma and $4.2 \mathrm{~mm}$ lateral to midline (Figure 1). To verify the correct positions of the electrodes, test pulses were applied to evoke field potentials during the implantation procedure, and postmortem histological analysis was also performed (Bock, 1989; Manahan-Vaughan et al., 1998).

Experiments were commenced 7-10 days after surgery. During all experiments the animals could move freely in the recording chamber $(40 \times 40 \times 50 \mathrm{~cm})$ and had free access to food and water. To allow the animals to acclimatize they were transferred to the experiment room the day before the experiment took place.

Before experiments were begun, animals were stringently assessed to confirm that recordings were obtained from $\mathrm{mf}-$ CA3 synapses. The $\mathrm{mf}$ synapse is highly sensitive to agonist activation of group II metabotropic glutamate (mGlu) receptors by $\left(2 \mathrm{~S}, 2^{\prime} \mathrm{R}, 3^{\prime} \mathrm{R}\right)-2-\left(2^{\prime}, 3^{\prime}\right.$-dicarboxycyclopropyl) glycine

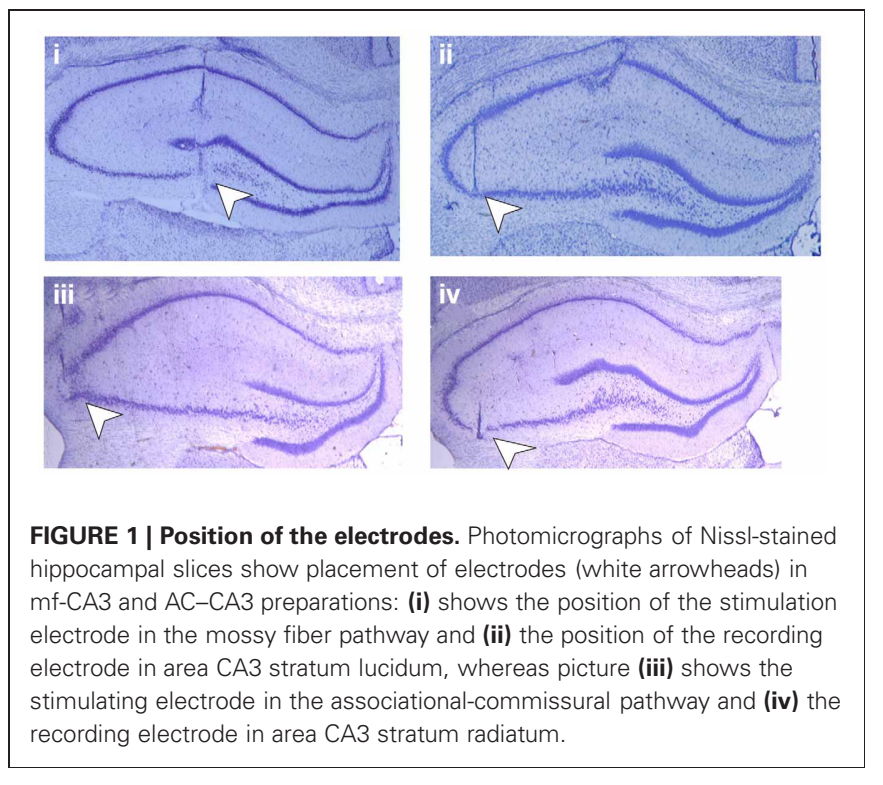

(DCG-IV) that selectively inhibits $\mathrm{mf}$ but not associationalcommissural EPSPs (Kamiya et al., 1996; Yeckel et al., 1999). Animals were excluded from the study when the fEPSP responses evoked in the stratum lucidum failed to show strong sensitivity (i.e., a reduction of test-pulse-evoked responses by $60 \%$ or greater) to DCG-IV (20 ng), applied into the lateral cerebral ventricle (i.c.v). To avoid an influence on fEPSPs mediated by DCG-IV on subsequent experiments, it was ensured that potentials had fully recovered before those experiments were performed. In addition, routine studies were conducted to verify that NMDAR-dependent LTP was not evident in these synapses, as described previously (Hagena and Manahan-Vaughan, 2010). Here, $30 \mathrm{~min}$ before tetanisation to induce LTP, the NMDAR antagonist, D-(-)-2-amino-5-phosphonopentanoic acid (D-AP5) was applied to examine whether LTP was influenced by the antagonist. Only animals whose LTP was unaffected were included in the current study. For recordings from freely behaving animals, the head stage was connected to an amplifier and stimulator via a flexible cable with a swivel connector. Recordings were analyzed and stored on computer and the EEG was monitored throughout experiments. To evoke fEPSPs a biphasic pulse was given with half-wave duration of $0.2 \mathrm{~ms}$. For recordings, the stimulation intensity was set to produce a fEPSP, which was $40 \%$ of the maximal obtainable. The intensity was found on the basis of an input-output curve (maximal stimulation $900 \mu \mathrm{A}$ ). Each recording consisted of an average of five consecutive pulses at $0.025 \mathrm{~Hz}$. To ensure stability of recordings, all animals were first tested in a baseline experiment where test-pulse stimulation was applied over the same time-period as subsequent plasticity experiments. To induce LTD, LFS consisting of 900 pulses at $1 \mathrm{~Hz}$, was given with a stimulus intensity that yielded potentials, which were $70 \%$ of the maximal fEPSP observed during the input-output curve analysis. LTP was induced by highfrequency stimulation (HFS) of afferent fibers. This comprised of 4 bursts of 100 pulses at $100 \mathrm{~Hz}$, with a 5 min interburst interval. To ensure a comparability of the evoked potentials, 
the stimulation was delivered in awake animals within a narrow time window of $\pm 15 \mathrm{~min}$ at the same time of the day (ca. 11 a.m.). This protocol was held constant across all animals and experiments.

Animals participating in LTP experiments had a minimum age of 12 weeks, as we observed that application of HFS in younger animals causes epileptiform seizures.

At least regarding effects in the CA1 or dentate gyrus regions, LTP and LTD can be divided into temporally different phases. A distinction can be made between an early phase (early-LTP) that is protein-synthesis independent (Matthies et al., 1990) and a late phase. The early phase has a duration of approximately $2 \mathrm{~h}$ (Morrell, 1991) The late phase (late-LTP) relies on proteinsynthesis and the induction of immediate early genes (IEGs) (Krug et al., 1984; Frey et al., 1988, 1993, 1996; Otani et al., 1989; Matthies et al., 1990; Kandel, 2001). We thus adopted this terminology in this study.

\section{DRUGS}

The reversible protein synthesis inhibitors, (2-[methoxybenzyl]3,4,pyrrolidinediol 3-acetate) anisomycin ( $4.8 \mu \mathrm{g} / 5 \mu \mathrm{l}$; SigmaAldrich, Taufkirchen, Germany) and emetine $(240 \mu \mathrm{g} / 5 \mu \mathrm{l})$ were first dissolved in $15 \mu \mathrm{l}$ of $1 \mathrm{~N} \mathrm{HCl}$ solution and then treated with $1 \mathrm{~N} \mathrm{NaOH}$ to correct for $\mathrm{pH}$. The solutions were subsequently made up to a $50 \mu \mathrm{l}$ volume with $0.9 \%$ sodium chloride. Actinomycin-D (Sigma-Aldrich) was fully dissolved in $0.9 \%$ sodium chloride. A pH of 7.0 was established using $1 \mathrm{~N}$ $\mathrm{NaOH}$. The total amount injected was $72 \mu \mathrm{g} / 12 \mu \mathrm{l}$ over a $6 \mathrm{~min}$ injection duration. The transcriptional inhibitor 5,6-dichloro-1beta-D-ribofuranosylbenzamidazole (DRB, $20 \mathrm{nM}$ ) was dissolved in $0.9 \%$ sodium chloride. The group II mGlu receptor agonist, (2S, $\left.2^{\prime} \mathrm{R}, 3^{\prime} \mathrm{R}\right)-2-\left(2^{\prime}, 3^{\prime}\right.$-dicarboxycyclopropyl)glycine (DCGIV, Tocris Cookson, Bristol, UK) was dissolved in isotonic saline $(0.9 \% \mathrm{NaCl})$ solution. The amount of DCG-IV that was used (20 ng) was chosen because it has no effect on evoked responses in the dentate gyrus (Klausnitzer and Manahan-Vaughan, 2008). Animals received unilateral injections via the intracerebral ventricle (i.c.v.), specifically via the ipsilateral ventricle by means of the implanted cannula.

The drug dose was dissolved in $5 \mu$ l of vehicle and applied over a 5 min period via a Hamilton syringe. To assess if this treatment affected basal synaptic transmission, evoked responses to test-pulse stimulation were assessed over a $24 \mathrm{~h}$ period. All injections were carried out $120 \mathrm{~min}$ prior to plasticity-evoking stimulation. Drug concentrations were chosen based on a previous study that revealed no effects of actinomycin $\mathrm{D}$, emetine or anisomycin on basal synaptic transmission over a $24 \mathrm{~h}$ period (Manahan-Vaughan et al., 2000). The behavioral state of the animal and intrahippocampal EEG were closely monitored to check for adverse reactions to treatment, but none were observed for any of the compounds.

\section{DATA ANALYSIS}

For each time-point, 5 consecutively evoked responses at $40 \mathrm{~s}$ intervals were averaged. The first $30 \mathrm{~min}$ of recording (6 timepoints) served as baseline, and the results were expressed as the mean percentage \pm the standard error of the mean (SEM) of the average baseline value. Baseline values in vehicle-injected animals were recorded for $2 \mathrm{~h}$ after injection. In some vehicle experiments, baseline values were obtained for $30 \mathrm{~min}$ after injection. Recordings were made every 5 min until 30 min after LFS or HFS and then every 15 min until $4 \mathrm{~h}$ had elapsed. On the following day an additional $1 \mathrm{~h}$ of recordings was obtained. To examine LTP, HFS of 4 pulses at $100 \mathrm{~Hz}$ was applied. To examine LTD, LFS of 900 pulses at $1 \mathrm{~Hz}$ was given.

For analysis of difference between groups a two-way analysis of variance (ANOVA) was applied to evaluate the interaction effects between group and time. The level of significance was set at $p<0.05$.

\section{RESULTS}

APPLICATION OF TRANSLATIONAL INHIBITORS AFFECT THE EARLY AND LATE PHASES OF LONG-TERM SYNAPTIC PLASTICITY AT MOSSY FIBER-CA3 SYNAPSES

Treatment with protein-synthesis inhibitors that act on translation, led to an inhibition of the early and late phases of synaptic plasticity in mf-CA3 synapses.

Robust LTP $(>24 \mathrm{~h})$ in vehicle-treated animals was induced with HFS comprising 4 pulses of $100 \mathrm{~Hz}$ (Figures 2A,E). Prior treatment with anisomycin resulted in a significant inhibition of the early and late phases of LTP compared to vehicle-treated animals (ANOVA, $F_{(1,7)}=6.04 ; p=0.04$; interaction effect: $F_{(26,182)}=1.558, p=0.049 ; n=5$, Figures 2A,E).

LFS at $1 \mathrm{~Hz}$ (900 pulses) elicited long-lasting LTD (>24 h) in vehicle-treated animals (Figures 2B,E). Treatment with anisomycin also resulted in an inhibition of both, the early and late phases of LTD (ANOVA, $F_{(1,7)}=12.95 ; p=0.008$; interaction effect: $F_{(26,182)}=2.9, p<0.0001 ; n=5$, Figures 2B,E).

To confirm these effects, another translation inhibitor, emetine, was used. Application of emetine $2 \mathrm{~h}$ before HFS or LFS inhibited the early and late phases of LTP and LTD compared to vehicle-treated controls (ANOVA, $F_{(1,10)}=5.31$; $p=0.04$; interaction effect: $F_{(26,260)}=2.31, p<0.001 ; n=6$, Figures $2 \mathrm{C}, \mathbf{F}$ and ANOVA, $F_{(1,5)}=10.56 ; p=0.02$; interaction effect: $F_{(26,130)}=1.81, p=0.016 ; n=4$, Figures 2D,F) for HFS and LFS experiments, respectively.

\section{INHIBITORS OF TRANSCRIPTION AFFECT ONLY THE LATE PHASE OF LONG-TERM SYNAPTIC PLASTICITY AT MOSSY FIBER-CA3 SYNAPSES}

To elucidate the effect of transcriptional inhibitors on proteinsynthesis at mf-CA3 synapses, actinomycin D and DRB were used. Application of actinomycin D $2 \mathrm{~h}$ before HFS or LFS resulted in an inhibition of late-LTP (Figures 3A,E) or late-LTD (Figures 3B,E), respectively, compared to controls (ANOVA, $F_{(1,8)}=5.63 ; p=0.04$; interaction effect: $p=0.16$; $n=6$ and ANOVA, $F_{(1,8)}=6.7 ; p=0.03$; interaction effect: $p=0.06 ; n=6)$.

Injection of DRB, similarly resulted in a significant inhibition of the late phase of either LTP (Figures 3C,F) or LTD (Figures 3D,F) after HFS or LFS, respectively, compared to control groups (for HFS experiments: ANOVA, $F_{(1,8)}=5.63$; $p=0.04$; interaction effect: $F_{(15,120)}=2.86, p<0.001 ; n=5$, Figures 3C,F; for LFS experiments: ANOVA, $F_{(1,6)}=8.82 ; p=$ 0.02 ; interaction effect: $p=0.64 ; n=4$, Figures 3D,F). 

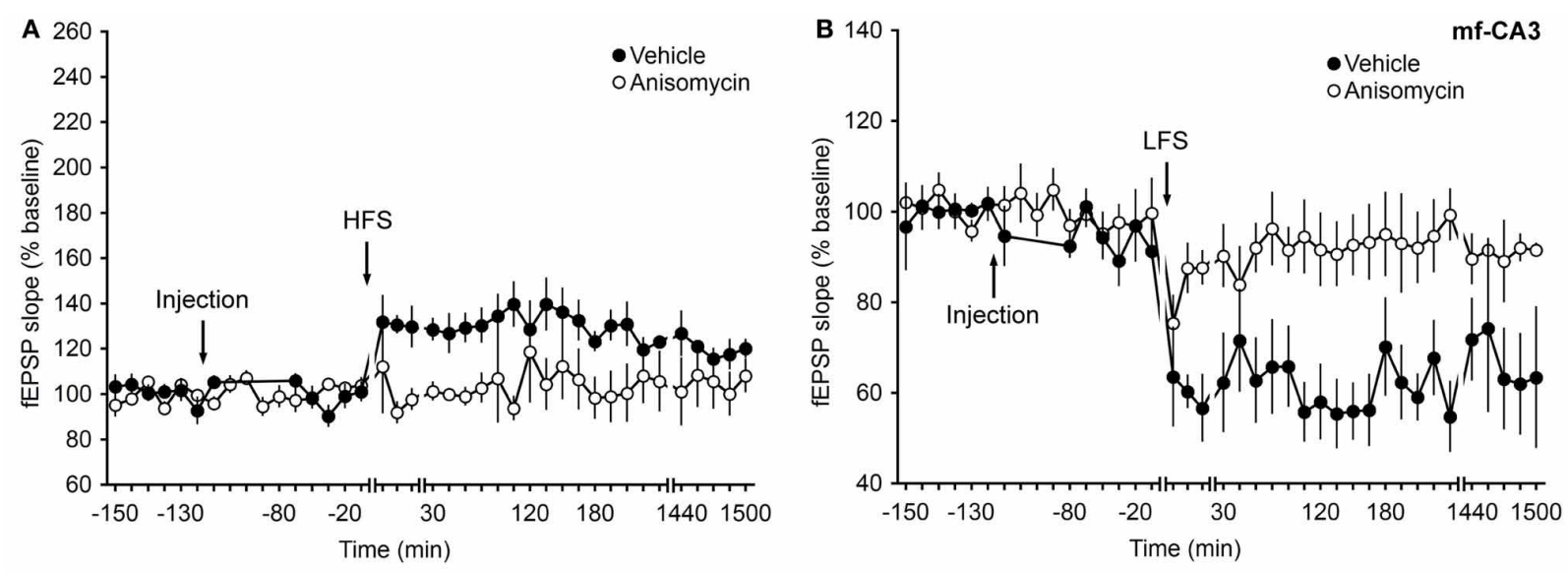

C
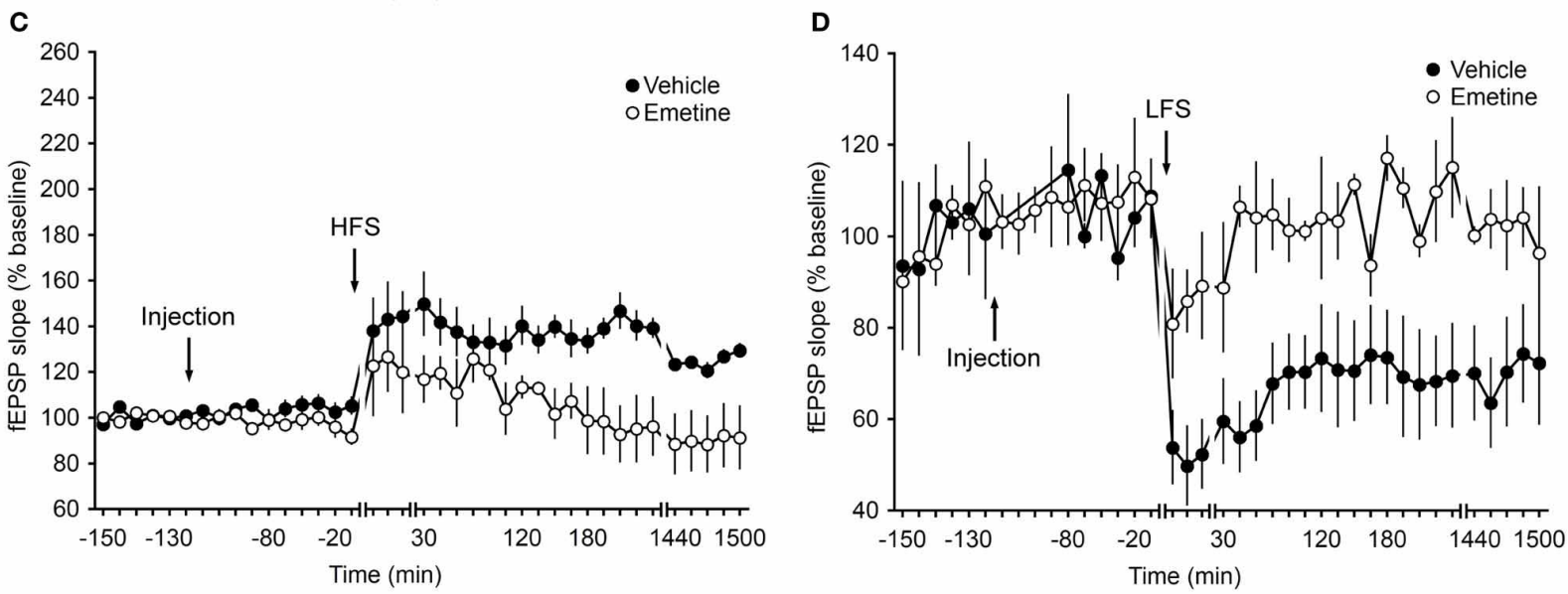

$\mathbf{E}$

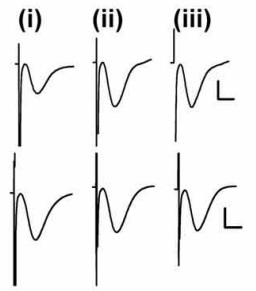

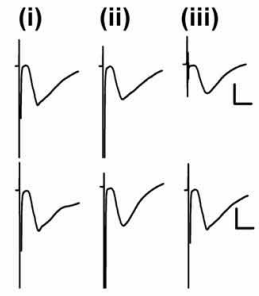

FIGURE 2 | Application of translational inhibitors affect the early and late phase of long-term synaptic plasticity at mossy fiber-CA3 synapses. (A) High-frequency stimulation (HFS, 4 trains, $100 \mathrm{~Hz}$ ) induces LTP that lasts for over $24 \mathrm{~h}$ in vehicle-injected animals. Application of the protein-synthesis inhibitor anisomycin $(4.8 \mu \mathrm{g})$ inhibits the early and late phase of LTP. (B) Application of LFS $(1 \mathrm{~Hz}, 900$ pulses) induces LTD (>24 h) in vehicle-injected animals. Injection of anisomycin inhibits early-and late LTP. (C) Application of HFS elicits LTP ( $>24 \mathrm{~h}$ ) in vehicle-injected animals. Injection of emetine $(240 \mu \mathrm{g})$ inhibits the early and late phase of LTP. (D) Injection of emetine leads to an impairment of both the early and late phase of LTD compared to vehicle-injected controls. Line breaks indicate change of time scale. (E)

Traces in the left panel represent responses recorded during an LTP control experiment (upper traces) and during an experiment where anisomycin was
$\mathbf{F}$

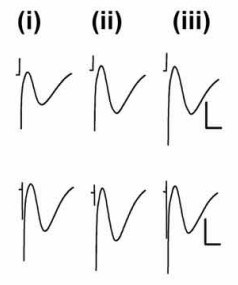

(i) (ii) (iii)

applied prior to HFS (lower traces): analog examples representing pre-HFS (i), $5 \mathrm{~min}$ post-HFS (ii) and $24 \mathrm{~h}$ post-HFS (iii) are shown. Vertical scale bar: $2 \mathrm{mV}$, horizontal scale bar: $8 \mathrm{~ms}$. Analog traces in the right panel are recorded during an experiment in which only LFS was applied (upper traces) and during an anisomycin experiment (lower traces) pre-LFS (i), 5 min post-LFS (ii) and $24 \mathrm{~h}$ post-LFS (iii). Vertical scale bar: $2 \mathrm{mV}$, horizontal scale bar: $8 \mathrm{~ms}$. (F) Analogs in the left panel depict fEPSPs recorded during a control experiment (upper traces) and during an emetine experiment (lower traces) pre-HFS (i), $5 \mathrm{~min}$ post-HFS (ii), and $24 \mathrm{~h}$ post-HFS (iii). Vertical scale bar: $2 \mathrm{mV}$, horizontal scale bar: $8 \mathrm{~ms}$. Analog traces in the right panel represent recordings taken (i) pre-LFS, (ii) $5 \mathrm{~min}$ post-LFS, and (iii) $24 \mathrm{~h}$ post-LFS in the presence of vehicle (upper traces) or emetine (lower traces). Vertical scale bar: $2 \mathrm{mV}$, horizontal scale bar: $8 \mathrm{~ms}$.

\section{TRANSLATION INHIBITORS PREVENT THE INTERMEDIATE AND LATE PHASES OF LTP, AND SOLELY THE LATE PHASE OF LTD AT ASSOCIATIONAL/COMMISSURAL-CA3 SYNAPSES}

Since CA3 pyramidal cells do not only form synapses with mossy fibers, but also receive inputs from other CA3 cells via the associational/commissural (AC) fibers (Hjorth-Simonsen, 1973; Swanson et al., 1978; Amaral, 1979; Laurberg, 1979; Ishizuka et al., 1990), we also assessed how protein synthesis inhibitors affect synaptic transmission within these synapses. 

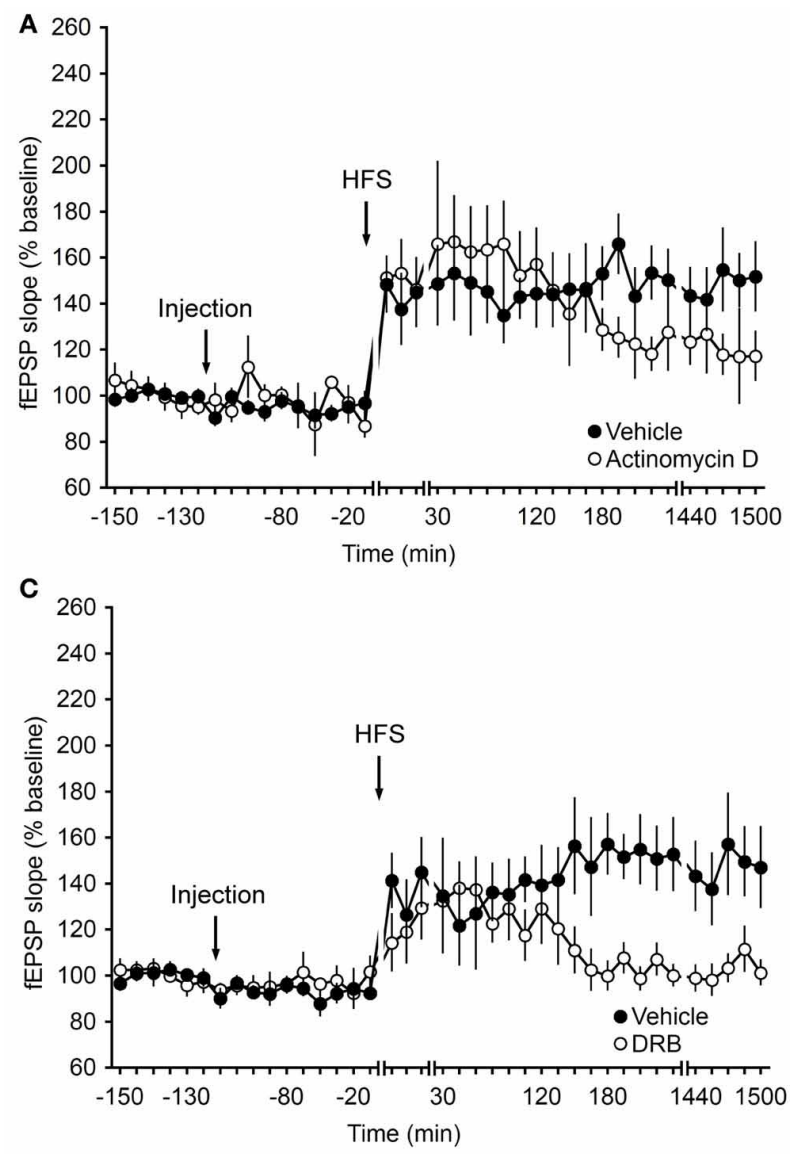

E

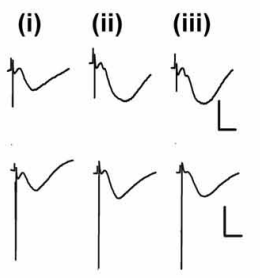

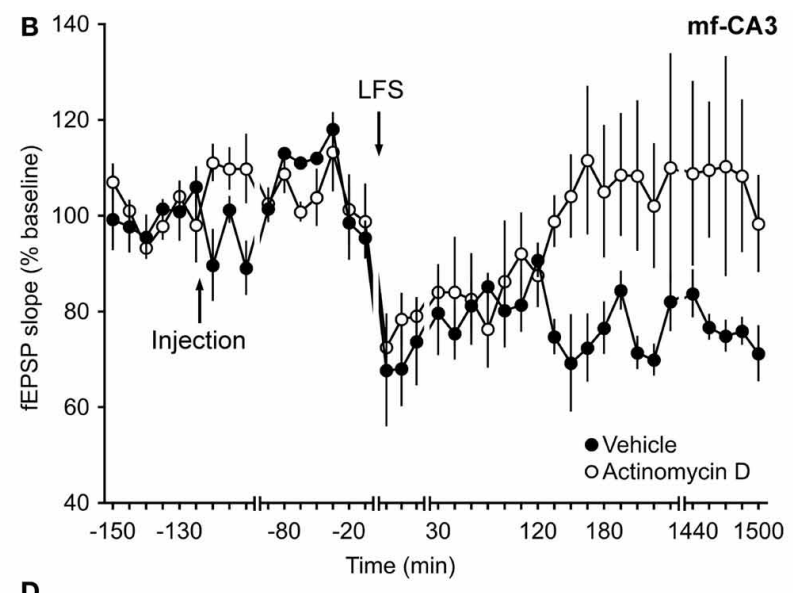

D

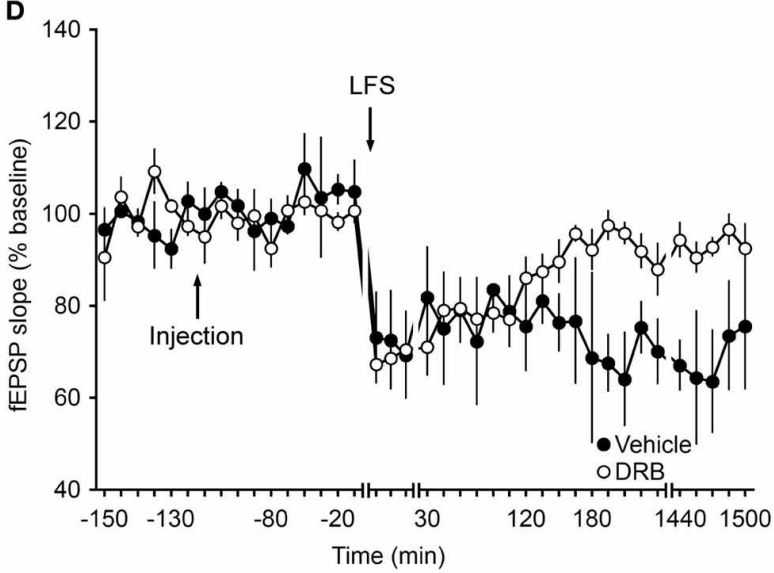

$\mathbf{F}$

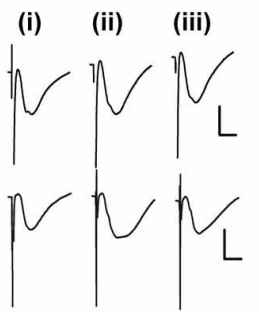

FIGURE 3 | Inhibitors of transcription affect only the late phase of long-term synaptic plasticity at mossy fiber-CA3 synapses. (A) In vehicle-injected animals, application of HFS facilitates LTP. When animals are treated with actinomycin D $(72 \mu \mathrm{g})$ an inhibition of the late phase of LTP occurs. (B) LFS elicits LTD in vehicle-injected animals. Application of actinomycin D inhibits the late phase of LTD. (C) HFS (4 trains of 100 pulses given at $100 \mathrm{~Hz}$ ) results in LTP. Injection of the transcription inhibitor DRB $(20 \mathrm{nM})$ inhibits the late phase of LTP. (D) In control groups, stimulation with 900 pulses at $1 \mathrm{~Hz}$ (LFS) elicits LTD. Injection of DRB inhibits the late phase of LTD. Line breaks indicate change in time scale. (E) Analog traces in the left panel were recorded (i) pre-HFS, (ii) 5 min post-HFS, and (iii) $24 \mathrm{~h}$ HFS in the presence of vehicle (upper traces) or actinomycin D (lower traces). Vertical scale bar: $2 \mathrm{mV}$, horizontal scale bar: $8 \mathrm{~ms}$. Analog traces in the right panel represent recordings taken (i) pre-LFS, (ii) 5 min post-LFS, and (iii) $24 \mathrm{~h}$ post-LFS in the presence of vehicle (upper traces) or Actinomycin D (lower traces). Vertical scale bar: $2 \mathrm{mV}$, horizontal scale bar: $8 \mathrm{~ms}$. (F) Analog traces in the left panel represent fEPSP responses obtained (i) pre-HFS, (ii) 5 min post-HFS, and (iii) $24 \mathrm{~h}$ post-HFS in the presence of vehicle (upper traces) or DRB (lower traces). Vertical scale bar: $2 \mathrm{mV}$, horizontal scale bar: $8 \mathrm{~ms}$. Analog traces in the right panel represent recordings taken (i) pre-LFS, (ii) $5 \mathrm{~min}$ post-LFS, and (iii) $24 \mathrm{~h}$ post-LFS in the presence of vehicle (upper traces) or DRB (lower traces). Vertical scale bar: $2 \mathrm{mV}$, horizontal scale bar: $8 \mathrm{~ms}$.
HFS applied to animals that received vehicle-injection resulted in LTP that lasted for over $24 \mathrm{~h}$. Injection of anisomycin ipsilaterally inhibited LTP starting at ca. $30 \mathrm{~min}$ post-HFS (ANOVA, $\quad F_{(1,13)}=11.63 ; p<0.01$; interaction effect: $\quad F_{(23,299)}=2.21, \quad p<0.01 ; \quad n=9$, Figures 4A,E).
Inhibition of late-LTD beginning ca. $2 \mathrm{~h}$ after LFS was also evident compared to vehicle-treated controls (ANOVA, $F_{(1,8)}=$ $6.78 ; p=0.03$; interaction effect: $p=0.22 ; n=5$, Figures 4B,E).

Emetine treatment confirmed these effects. Here, an inhibition of LTP that began in intermediate phases was apparent (Figures 4C,F). Late-LTD only was affected (Figures 4D,F). 


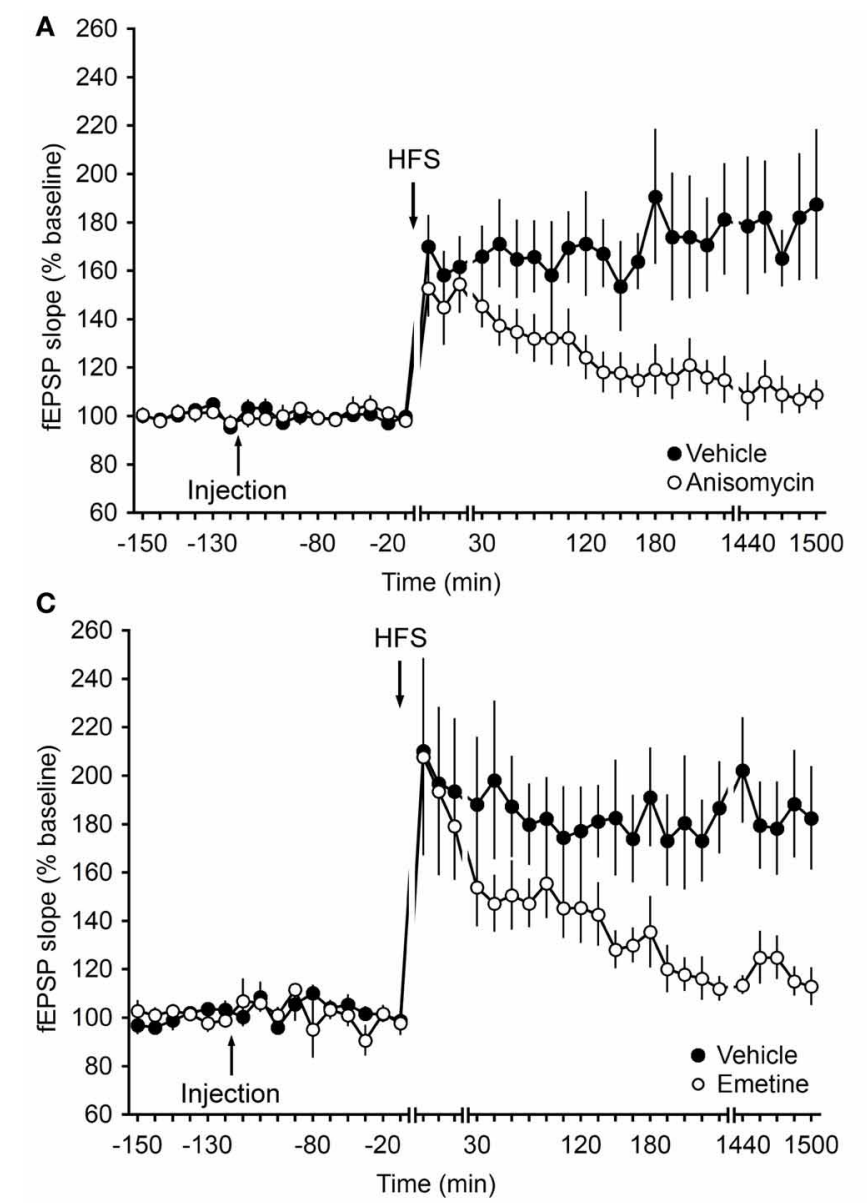

E (i) (ii) (iii)<smiles>CCCC(C)CC(C)CCC</smiles>

(i) (ii) (iii)

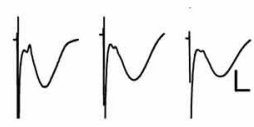

hoh h

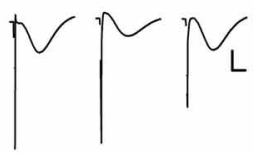

FIGURE 4 | Translation inhibitors prevent the intermediate and late phases of LTP and solely the late phase of LTD at associational/ commissural-CA3 synapses. (A) Application of HFS results in LTP $(>24 \mathrm{~h})$. Treatment with the translational inhibitor anisomycin inhibits the late phase of LTP. (B) LFS elicits LTD $(>24 \mathrm{~h})$ in control animals. Injection of anisomycin inhibits the late phase of LTD. (C) Injection of emetine inhibits the late phase of LTP compared to controls. (D) In the presence of emetine, the late phase of LTD is inhibited compared to controls. Line breaks indicate change of time scale. (E) Analog traces in the left panel represent recordings taken (i) pre-HFS,

(ii) $5 \mathrm{~min}$ post-HFS, and (iii) $24 \mathrm{~h}$ post-HFS in the presence of vehicle (upper traces) or in anisomycin-injected animals (lower traces). Vertical

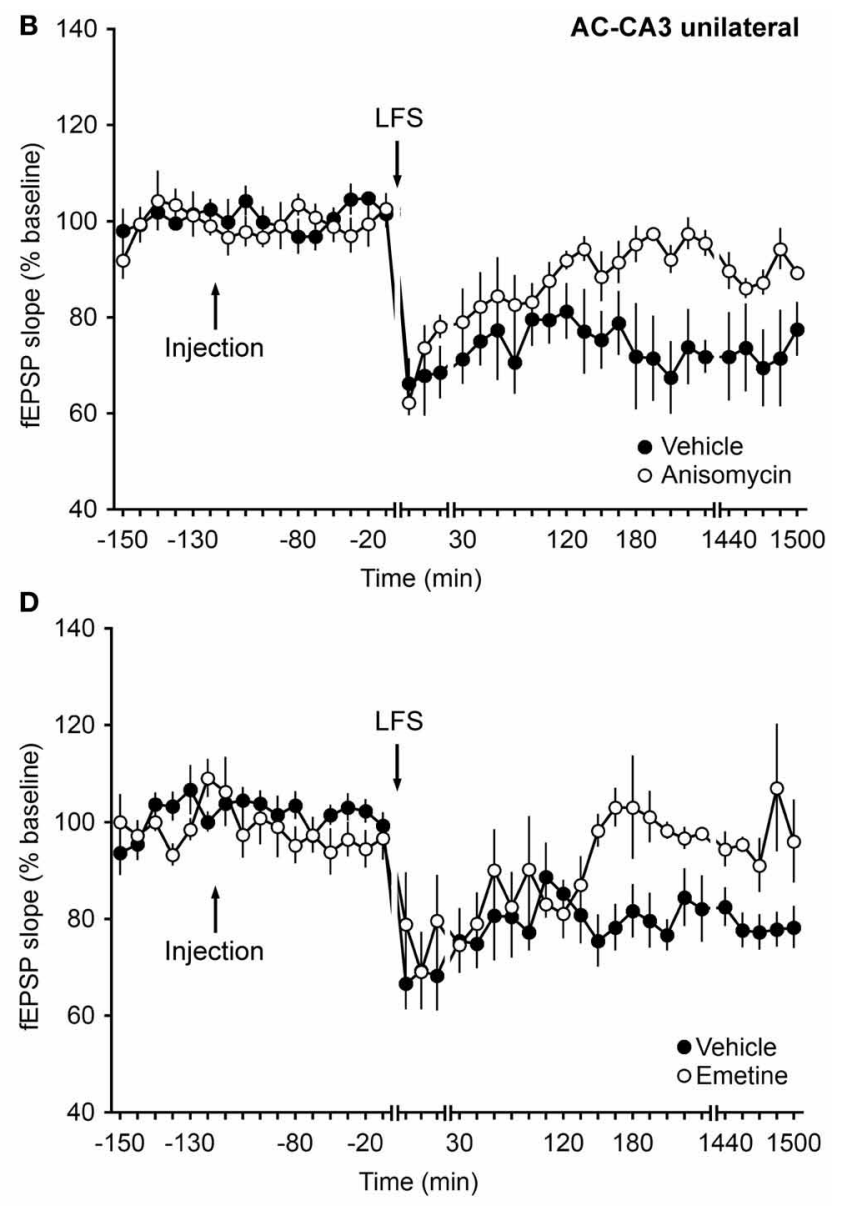

$\mathbf{F}$

(i) (ii) (iii)

(i) (ii) (iii)

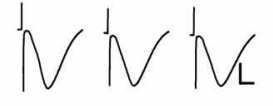

N ${ }^{\prime}{ }^{\prime}$

scale bar: $2 \mathrm{mV}$, horizontal scale bar: $8 \mathrm{~ms}$. Traces in the right panel show analogs that represent fEPSP responses obtained pre-LFS (i), $5 \mathrm{~min}$ post-LFS (ii), and $24 \mathrm{~h}$ (iii) after LFS in the presence of vehicle (upper traces) or anisomycin (lower traces). Vertical scale bar: $2 \mathrm{mV}$, horizontal scale bar: $8 \mathrm{~ms}$. (F) Analog traces in the left panel represent fEPSP responses recorded pre-HFS (i), $5 \mathrm{~min}$ post-HFS (ii), and $24 \mathrm{~h}$ after HFS (iii) in the presence of vehicle (upper traces) or emetine (lower traces). Vertical scale bar: $2 \mathrm{mV}$, horizontal scale bar: $8 \mathrm{~ms}$. Analogs in the right panel represent fEPSP responses recorded pre-LFS (i), $5 \mathrm{~min}$ post-LFS (ii), and $24 \mathrm{~h}$ after LFS (iii) in the presence of vehicle (upper traces) or emetine (lower traces). Vertical scale bar: $2 \mathrm{mV}$, horizontal scale bar: $8 \mathrm{~ms}$.

(LTP: ANOVA, $F_{(1,9)}=7.86 ; p=0.02$; interaction effect: $F_{(13,177)}=2.16, p=0.02 ; n=6$; LTD: ANOVA, $F_{(1,5)}=$ 9.25; $p=0.02$; interaction effect: $F_{(14,70)}=1.94, p=0.04$; $n=5)$.
TRANSCRIPTION INHIBITORS BLOCK EARLY AND LATE LTP, AND LATE-LTD ONLY AT ASSOCIATIONAL-COMMISSURAL-CA3 SYNAPSES

In control animals, that received only vehicle injection, HFS or LFS led to LTP or LTD, respectively, that lasted for over $24 \mathrm{~h}$ 
(Figures 5A,B). Injection of actinomycin D, ipsilaterally, inhibited the early and late phase of LTP (ANOVA compared to vehicle-injected controls, $F_{(1,3)}=17.20 ; p=0.02$; interaction effect: $p=0.43$, Figures 5A,E).

Application of actinomycin D, ipsilaterally, inhibited late LTD only (ANOVA compared to vehicle-injected controls,
$F_{(1,6)}=9.34 ; p=0.02$; interaction effect: $p=0.07 ; n=6$, Figures 5B,E). Although some effects on intermediate LTD were evident, this was not significant.

Effects were confirmed using DRB, where a significant impairment of the early and late phase of LTP was evident following ipsilateral injection (ANOVA compared to vehicle-injected

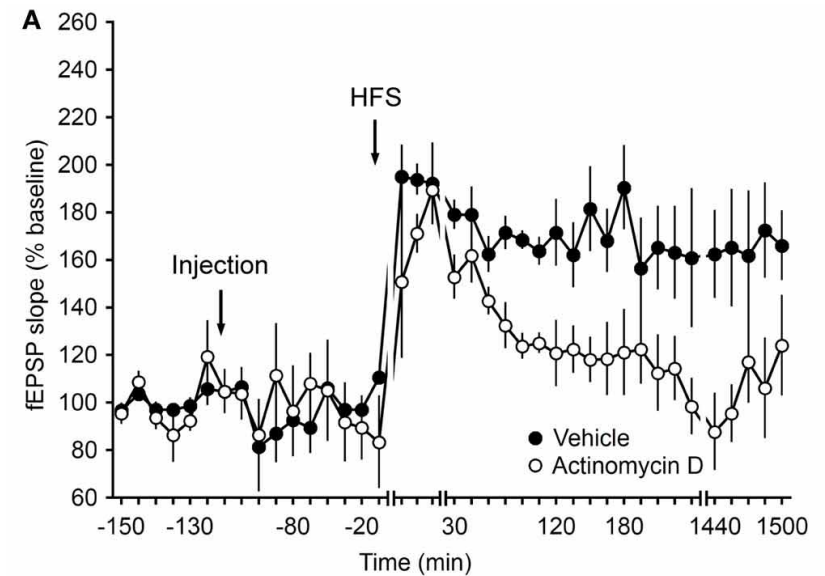

C

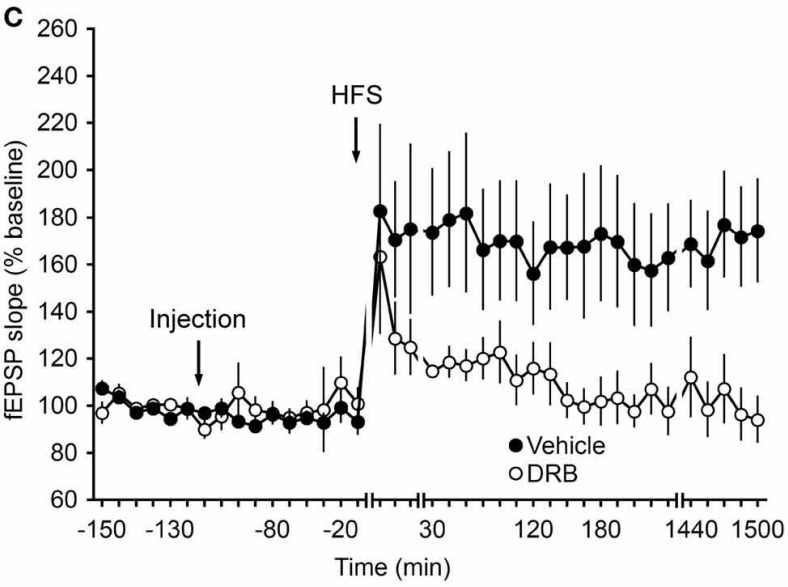

E

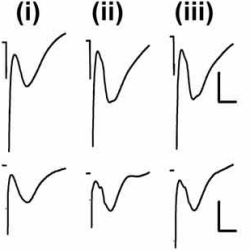

(i) (ii) (iii)

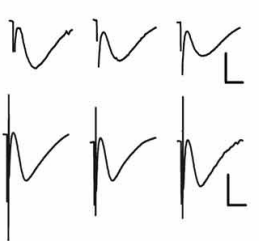

FIGURE 5 | Transcription inhibitors block early and late LTP, and late-LTD only, at associational/commissural-CA3 synapses. (A) In control experiments, application of HFS results in LTP $(>24 \mathrm{~h}$ ). Injection of actinomycin D inhibits the early and late phase of LTP. (B) Application of LFS results in the expression of LTD ( $>24 \mathrm{~h}$ ). In the presence of actinomycin $D$, early and late phases of LTD are inhibited. (C) Injection of DRB inhibits the early and late phase of LTP compared to controls. (D) In the presence of DRB, early and late phases of LTD are inhibited compared to controls. Line breaks indicate change in time-scale. (E) Traces in the left panel represent fEPSP responses recorded pre-HFS (i), 5 min post-HFS (ii), and $24 \mathrm{~h}$ after HFS (iii) in the presence of vehicle (upper traces) or actinomycin D (lower
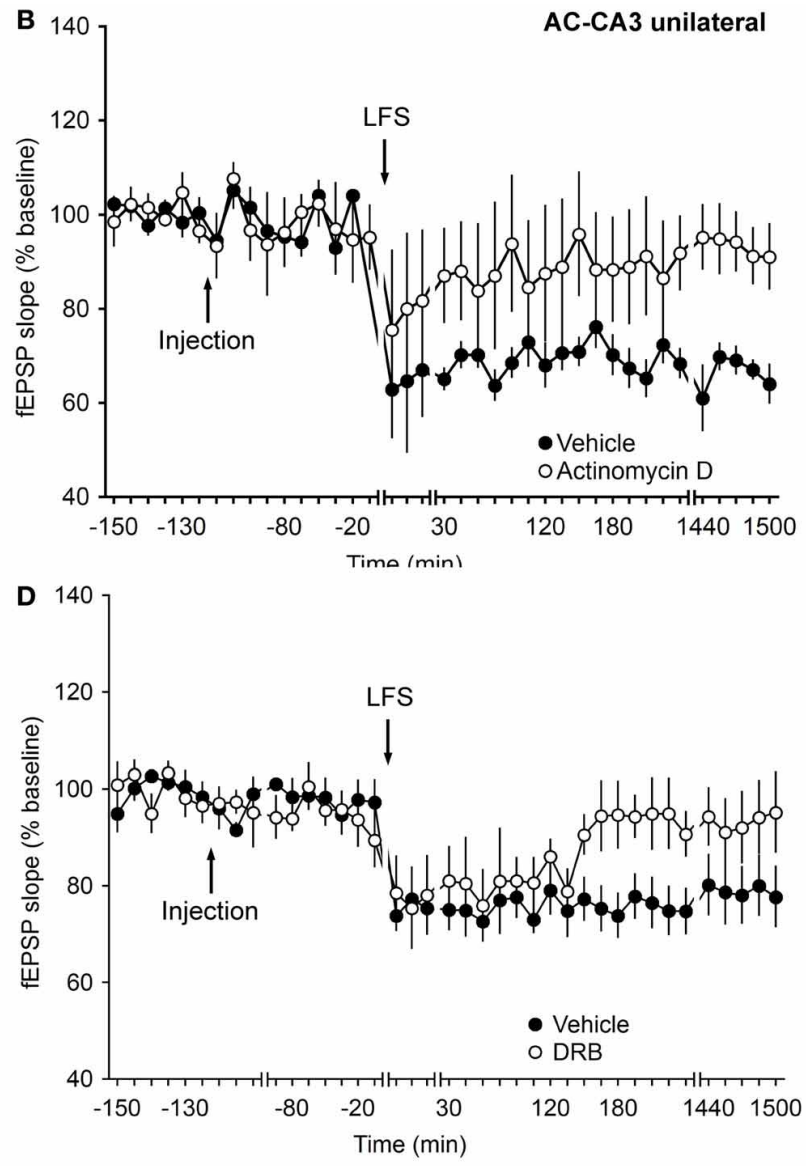

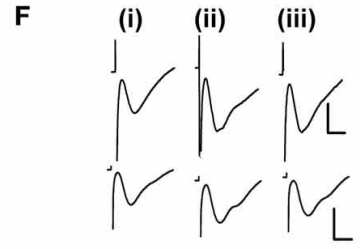

traces). Vertical scale bar: $2 \mathrm{mV}$, horizontal scale bar: $8 \mathrm{~ms}$. Analogs in the right panel represent fEPSP responses recorded pre-LFS (i), 5 min post-LFS (ii), and $24 \mathrm{~h}$ after LFS (iii) in the presence of vehicle (upper traces) or actinomycin D (lower traces). Vertical scale bar: $2 \mathrm{mV}$, horizontal scale bar: $8 \mathrm{~ms}$. (F) Traces depicted in the left panel represent fEPSP responses recorded pre-HFS (i), $5 \mathrm{~min}$ post-HFS (ii), and $24 \mathrm{~h}$ after HFS (iii) in the presence of vehicle (upper traces) or DRB (lower traces). Vertical scale bar: $2 \mathrm{mV}$, horizontal scale bar: $8 \mathrm{~ms}$. Analogs in the right panel represent fEPSP responses recorded pre-LFS (i), $5 \mathrm{~min}$ post-LFS (ii), and $24 \mathrm{~h}$ after LFS (iii) in the presence of vehicle (upper traces) or DRB (lower traces). Vertical scale bar: $2 \mathrm{mV}$, horizontal scale bar: $8 \mathrm{~ms}$. 
controls, $F_{(1,8)}=6.01 ; p=0.03$; interaction effect: $F_{(26,208)}=$ 3.97, $p<0.001 ; n=5$, Figures 5C,F). LFS in the presence of $\mathrm{DRB}$, resulted, in contrast, in an inhibition only of the late phase of LTD compared to control animals [ANOVA, $F_{(1,11)}=5.12$; $p=0.04$; interaction effect: $p=0.81 ; n=8$, Figures 5D,F $]$.

\section{APPLICATION OF PROTEIN SYNTHESIS INHIBITORS HAS NO EFFECT ON BASAL SYNAPTIC TRANSMISSION IN MOSSY FIBER-CA3 SYNAPSES}

To assess, whether protein synthesis inhibitors affect basal synaptic transmission in mf-CA3 synapses, in the concentrations used here, the translation inhibitors, anisomycin or emetine, and the transcription inhibitors, actinomycin D or DRB, were applied in an experiment in which animals received only test-pulse stimulation. Here, no effects on the evoked potentials were observed over the 24 monitoring period [ANOVA, $F_{(4,13)}=0.64 ; p=0.64$; $n=7$, Figures $6 \mathrm{~A}, \mathbf{B}]$.

\section{DISCUSSION}

These data describe for the first time, the protein synthesis dependency of persistent forms of synaptic plasticity at mf-CA3 and
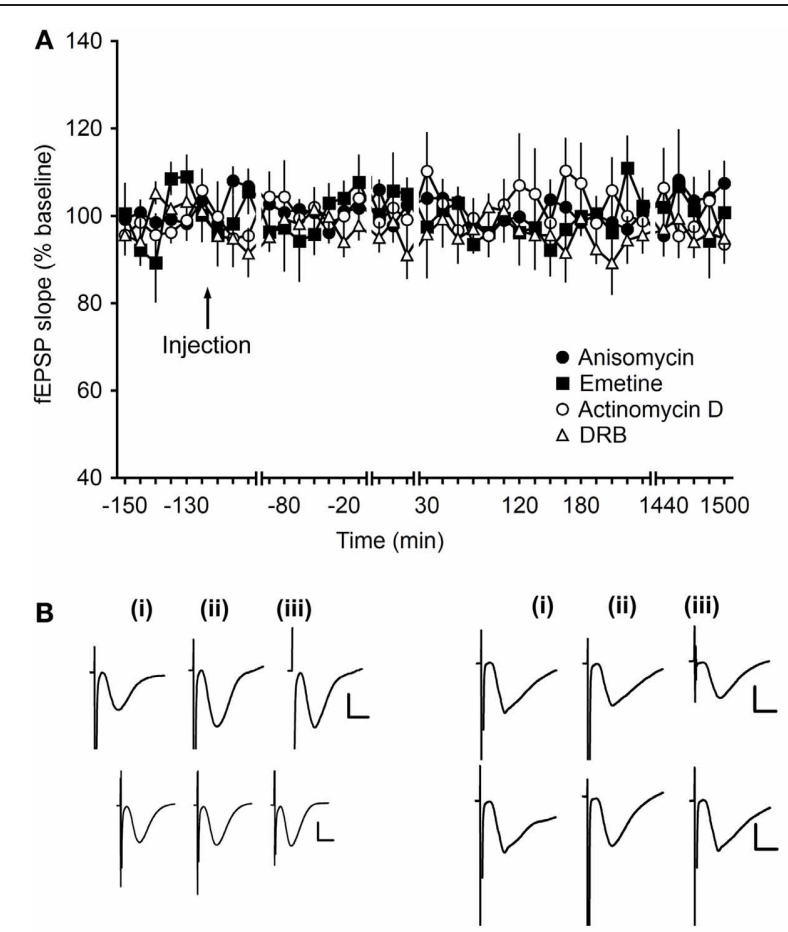

FIGURE 6 | Application of translational- and transcriptional-Inhibitors do not alter basal synaptic transmission. (A) After injection of anisomycin $(4.8 \mu \mathrm{g})$, emetine $(240 \mu \mathrm{g})$, actinomycin D $(72 \mu \mathrm{g})$ or DRB $(20 \mathrm{nM})$, fEPSPs recorded during test-pulse stimulation showed stable responses for over $24 \mathrm{~h}$. Line breaks indicate change in time scale. (B) Analog traces recorded during test-pulse experiments show fEPSP responses $5 \mathrm{~min}$ pre-injection (left traces), 5 min post-injection (middle traces) and $24 \mathrm{~h}$ after injection (right traces), in the anisomycin experiment (upper left), in the emetine experiment (lower left), in the actinomycin D experiment (upper right), and in the DRB experiment (lower right). Vertical scale bar: $2 \mathrm{mV}$, horizontal scale bar: $8 \mathrm{~ms}$.
AC-CA3 synapses. An interesting picture emerges, that suggests that mf-CA3 and AC-CA3 synapses have distinct requirements for protein translation and transcription. These findings suggest that functionally distinct sources of information to the CA3 region occur, that may relate to its very distinct role in information storage and memory.

Rapid effects of translation inhibitors were seen with regard to both LTP and LTD in mf synapses in our study. This is in line with reports that early mf-CA3 LTP depends on protein translation in vivo (Barea-Rodríguez et al., 2000). Protein translation not only occurs in the cell body but also occurs in dendrites after stimulation of afferent fibers (Aakalu et al., 2001; Job and Eberwine, 2001; Smith et al., 2001; Steward and Schuman, 2001; Steward and Worley, 2001). Furthermore, HFS triggers the synthesis of new proteins within minutes (Lynch et al., 1994; Osten et al., 1996; Lanahan and Worley, 1998; Ouyang et al., 1999). MF LTD shares the same mechanisms regarding its induction as LTP (Kobayashi et al., 1996). MF LTD also requires cAMP, which is decreased through activity of presynaptic metabotropic glutamate receptors (mGlus), and requires Rab3A activation (Tzounopoulos et al., 1998). This suggests that LTD, like LTP, might be influenced by the activity of translational inhibitors. A requirement of LTD for rapid protein translation has been described at other hippocampal synapses (Huber et al., 2000). In the light of recent findings on the role of CA3 in spatial learning (Hagena and Manahan-Vaughan, 2011) one can speculate that mossy fibers may be involved in rapid learning of novel information and help in holding that information online for comparison with information stored in AC-CA3 synapses (Hagena and ManahanVaughan, 2011). This would in turn explain a need for rapid protein translation.

Inhibition of protein transcription in mf-CA3 synapses prevented the late phases of LTP and LTD and left early phases intact. This is in line with studies that suggest that protein transcription requires several hours (Bliss and Collingridge, 1993; Huang et al., 1994; Nguyen et al., 1994; Nguyen and Kandel, 1996). The stabilization of LTP depends on protein transcription (Calixto et al., 2003). It is not unreasonable to expect that proteins and RNAs necessary for the maintenance of mf LTP are synthesized in the granule cell soma, as high frequency stimulation at other hippocampal synapses upregulates the expression of proteins mediating the release of vesicular neurotransmitters such as synapsin I, synaptotagmin and synaptophysin (Lynch et al., 1994; Hicks et al., 1997). Thus, disruption of a small pool of neurotransmitter-releasing proteins may contribute to an impaired stabilization of LTP. This presynaptic contribution to $\mathrm{mf}$ LTP may mediate the maintenance phase, whereas the induction of mf LTP is regulated by postsynaptic mechanisms (Lonart, 2002; Calixto et al., 2003). The importance of the dentate granule cell soma is emphasized by a recent study which shows that action potential-dependent $\mathrm{Ca}^{2+}$ influx in granule cell somata as well as fast axonal transport of newly synthesized proteins to $\mathrm{mf}$ synapses are required for stable mf LTP (Barnes et al., 2010).

In contrast to results obtained at mf-CA3 synapses, translational inhibitors only affect the late phase of LTP or LTD at AC-CA3 synapses, suggesting that information processing at the AC-synapses is distinct from processing at mf-CA3 synapses. This 
is not unlikely since it has been speculated that the recurrent network formed by associational fibers is particularly engaged in pattern completion (Guzowski et al., 2004; Lee et al., 2004; Leutgeb et al., 2004; Gold and Kesner, 2005; Rolls and Kesner, 2006), whereas mossy fibers may be important in pattern separation (Bischofberger et al., 2006; Gilbert and Kesner, 2006; Kesner and Hopkins, 2006; Rolls and Kesner, 2006) and the processing of one-trial working memory and the encoding of novel spatial information within a short time-frame (McNaughton and Morris, 1987; Rolls and Kesner, 2006; Kesner, 2007). The postulated role of mf-CA3 synapses in fast processing of rapidly learned information may necessitate rapid protein translation that is not required by AC-synapses.

Strikingly, effects of protein transcription inhibitors on earlyLTP and late-LTD were found at AC-CA3 synapses. The fact that LTP and LTD at AC-CA3 synapses are not identically affected by translation and transcription inhibitors, suggests that they play distinct roles in information processing. This possibility is supported by studies of the functional relationship of AC-CA3 synaptic plasticity and spatial memory formation (Hagena and Manahan-Vaughan, 2011). Taken together, a very interesting profile for the protein synthesis-dependency of the CA3 synapses emerges: at $\mathrm{mf}$ synapses, dendritic translation assists the early induction of both LTP and LTD akin to effects observed for LTD in the CA1 region (Huber et al., 2000). Dendritic translation does not appear to be required for induction of either LTP or LTD at associational commissural synapses. By contrast, whereas $\mathrm{mf}$ synapses do not need transcription for induction of plasticity, at associational-commissural synapses early LTP requires transcription whereas early LTD does not. This latter finding suggests a need for greater stability for AC-LTP compared to LTD at associational-commissural synapses and LTP/LTD at $\mathrm{mf}$ synapses.

After HFS, protein-synthesis has a rapid onset with new proteins being built within a time-course of 15-45 min (Lynch et al., 1994; Osten et al., 1996; Lanahan and Worley, 1998; Ouyang et al., 1999). In addition, upregulation of certain RNAs as early as 30 min after plasticity induction has been reported (Sadile et al., 1995; Morimoto et al., 1998; French et al., 2001; Steward and Worley, 2001). Furthermore, IEGs also undergo rapid transcription (Saha et al., 2011), that is implemented for IEG expression changes after LTP induction (Messaoudi et al., 2002) and the IEG Arc is expressed in the CA3 region within seconds of novel context exposure (Pevzner et al., 2012). These findings suggest that very rapid transcriptional effects are feasible and may play a role in synaptic plasticity, particularly in CA3.

The dependency of early AC-LTP on transcription is in line with the possibility that an LTP-specific tag is set by HFS at this synapse. In in vivo synapses, one cannot exclude that the synapses are not naïve. A stimulus that is subthreshold for the generation of persistent synaptic plasticity may nonetheless be sufficient to produce a tag in selected synapses. This tag then could capture proteins after a subsequent attempt to induce synaptic plasticity, and support long-lasting modifications of the synapse (Frey and Morris, 1997, 1998; Martin et al., 1997; Casadio et al., 1999; Sajikumar and Frey, 2004; Sajikumar et al., 2007). Protein transcription inhibition would prevent this process, and effects may be detected within minutes of an attempt to induce persistent plasticity. The dependency of early AC-LTP on transcription may be mediated by the setting of such a tag. This could comprise an mRNA or a protein (Sajikumar and Korte, 2011; Li et al., 2012).

We cannot completely exclude however, that the changes of fEPSPs observed after application of transcriptional or translational inhibitors may have been caused by other effects. For example, with regard to anisomycin, it has been shown that, additionally to the well-described action on transcription, it also exhibits neuroprotective effects via regulation of mitogenactivated protein kinases (MAP kinases) and extracellular signal regulated kinases (ERK) (Cano et al., 1994; Hong et al., 2007). Membrane excitability could also have been affected by intrinsic or toxic effects of the compounds (Abbas et al., 2011). However in other studies, where other synapses of the trisynaptic network were scrutinized it was reported that the time course of LTP is unaffected by actinomycin D or anisomycin at the doses used in the current study, suggesting that toxic effects on neurons are negligible under these conditions (Otani et al., 1989; Frey et al., 1996). Furthermore, a specific examination of membrane excitability revealed no effects of actinomycin D (Nikitin and Kozyrev, 2005). However, although emetine was reported to have no effects on intracellularly recorded membrane properties (Stanton and Sarvey, 1984), a more recent study described effects of emetine on basal synaptic transmission in hippocampal slices of young rats in vitro (Abbas et al., 2011). We neither saw effects of emetine on basal synaptic transmission in the current study nor in a study of the role of protein synthesis in the CA1 region (Manahan-Vaughan et al., 2000). In both cases stable basal synaptic transmission was followed for $24 \mathrm{~h}$ after emetine, anisomycin or actinomycin D treatment. Thus, at the concentration and under the conditions addressed in our study, we assume that no effects on membrane excitability occurred.

The synthesis of new proteins and specifically new mRNA is likely to support synaptic restructuring that is required for the long-term stabilization of synaptic plasticity and new information storage (Bailey et al., 1992; Vanderklish and Edelman, 2002; Sutton and Schuman, 2006). A picture is emerging, whereby it is becoming clear that the protein translation and transcription requirements of the different hippocampal subregions and their respective synapses is very distinct (Otani and Abraham, 1989; Frey et al., 1993; Huang and Kandel, 1994; Nguyen et al., 1994; Manahan-Vaughan et al., 2000; Calixto et al., 2003; Pöschel and Manahan-Vaughan, 2007). In effect, there are few common denominators with regard to the protein synthesisdependency of LTP and LTD in the different hippocampal subregions. This may relate to the different putative roles of plasticity in these different subregions in information encoding (Kemp and Manahan-Vaughan, 2007; Hagena and Manahan-Vaughan, 2011).

In conclusion, this study describes for the first time a differentiation in the protein translation and protein transcription requirements of persistent LTP and LTD at CA3 synapses in vivo. We report that whereas early and late phases of mf-CA3 plasticity are prevented by translation inhibitors, only late phases of mf-CA3 plasticity require transcription. In contrast, only late plasticity of AC-CA3 synapses is affected by protein translation inhibitors, whereas early LTP and late-LTD are affected by 
transcription inhibitors. These differences are likely to reflect the distinct functional roles of mf-CA3 plasticity and AC-CA3 plasticity in short- and long-term information storage in the hippocampus.

\section{REFERENCES}

Aakalu, G., Smith, W. B., Nguyen, N., Jiang, C., and Schuman, E. M. (2001). Dynamic visualization of local protein synthesis in hippocampal neurons. Neuron 30, 489-502.

Abbas, A. K., Huang, F. S., Li, R., Ekström, J., and Wigström, $\mathrm{H}$. (2011). Emetine treatment masks initial LTP without affecting longterm stability. Brain Res. 1426, $18-29$.

Abraham, W. C., and Williams, J. M. (2003). Properties and mechanisms of LTP maintenance. Neuroscientist 9, 463-474.

Amaral, D. G. (1979). Synaptic extensions from the mossy fibers of the fascia dentata. Anat. Embryol. 155, 241-251.

Bailey, C. H., Montarolo, P., Chen, M., Kandel, E. R., and Schacher, S. (1992). Inhibitors of protein and RNA synthesis block structural changes that accompany long-term heterosynaptic plasticity in Aplysia. Neuron 9, 749-758.

Barea-Rodríguez, E. J., Rivera, D. T., Jaffe, D. B., and Martinez, J. L. (2000). Protein synthesis inhibition blocks the induction of mossy fiber long-term potentiation in vivo. J. Neurosci. 20, 8528-8532.

Barnes, S. J., Opitz, T., Merkens, M., Kelly, T., Brelie von der, C., Krueppel, R., et al. (2010). Stable mossy fiber long-term potentiation requires calcium influx at the granule cell soma, protein synthesis, and microtubule-dependent axonal transport. J. Neurosci. 30, 12996-13004.

Bischofberger, J., Engel, D., Frotscher, M., and Jonas, P. (2006). Timing and efficacy of transmitter release at mossy fiber synapses in the hippocampal network. Pflugers Arch. $453,361-372$.

Blackstad, T. W. (1956). Commissural connections of the hippocampal region in the rat, with special reference to their mode of termination. J. Comp. Neurol. 105, 417-537.

Blackstad, T. W., and Kjaerheim, A. (1961). Special axo-dendritic synapses in the hippocampal cortex: electron and light microscopic studies on the layer of mossy fibers. J. Comp. Neurol. 117, 133-159.

Bliss, T. V., and Collingridge, G. L. (1993). A synaptic model of memory: long-term potentiation in the hippocampus. Nature 361, 31-39.

Bock, P. (1989). Bock: RomeisMikroskopische Technik. 17. neubearbeite Auflage - Google Scholar.

Calixto, E., Thiels, E., Klann, E., and Barrionuevo, G. (2003). Early maintenance of hippocampal mossy fiber-long-term potentiation depends on protein and RNA synthesis and presynaptic granule cell integrity. J. Neurosci. 23, 4842-4849.

Cano, E., Hazzalin, C. A., and Mahadevan, L. C. (1994). Anisomycin-activated protein kinases p45 and p55 but not mitogen-activated protein kinases ERK- 1 and -2 are implicated in the induction of c-fos and c-jun. Mol. Cell. Biol. 14, 7352-7362.

Casadio, A., Martin, K. C., Giustetto, M., Zhu, H., Chen, M., Bartsch, D., et al. (1999). A transient, neuronwide form of CREB-mediated longterm facilitation can be stabilized at specific synapses by local protein synthesis. Cell 99, 221-237.

Davis, H. P., and Squire, L. R. (1984). Protein synthesis and memory: a review. Psychol. Bull. 96, 518-559.

Debanne, D., Gähwiler, B. H., and Thompson, S. M. (1998). Longterm synaptic plasticity between pairs of individual CA3 pyramidal cells in rat hippocampal slice cultures. J. Physiol. 507( $\mathrm{Pt} 1)$, 237-247.

French, P. J., O'Connor, V., Jones, M. W., Davis, S., Errington, M. L., Voss, K., et al. (2001). Subfield-specific immediate early gene expression associated with hippocampal longterm potentiation in vivo. Eur. J. Neurosci. 13, 968-976.

Frey, U., and Morris, R. G. (1997). Synaptic tagging and long-term potentiation. Nature 385, 533-536.

Frey, U., and Morris, R. G. (1998). Weak before strong: dissociating synaptic tagging and plasticityfactor accounts of late-LTP. Neuropharmacology 37, 545-552.

Frey, U., Frey, S., Schollmeier, F., and Krug, M. (1996). Influence of actinomycin D, a RNA synthesis inhibitor, on long-term potentiation in rat hippocampal neurons in vivo and in vitro. J. Physiol. 490(Pt 3), 703-711.

Frey, U., Huang, Y. Y., and Kandel, E. R. (1993). Effects of cAMP

\section{ACKNOWLEDGMENTS}

This work was funded by the German Research Foundation (DFG). We thank Jens Klausnitzer for technical assistance and Nadine Gomell for animal care.

simulate a late stage of LTP in hippocampal CA1 neurons. Science 260, 1661-1664.

Frey, U., Krug, M., Reymann, K. G., and Matthies, H. (1988). Anisomycin, an inhibitor of protein synthesis, blocks late phases of LTP phenomena in the hippocampal CA1 region in vitro. Brain Res. 452, 57-65.

Gilbert, P. E., and Kesner, R. P. (2006). The role of the dorsal CA3 hippocampal subregion in spatial working memory and pattern separation. Behav. Brain Res. 169, 142-149.

Gilbert, P. E., Kesner, R. P., and Lee, I. (2001). Dissociating hippocampal subregions: double dissociation between dentate gyrus and CA1. Hippocampus 11, 626-636.

Gold, A. E., and Kesner, R. P. (2005). The role of the CA3 subregion of the dorsal hippocampus in spatial pattern completion in the rat. Hippocampus 15, 808-814.

Goodrich-Hunsaker, N. J., Hunsaker, M. R., and Kesner, R. P. (2008). The interactions and dissociations of the dorsal hippocampus subregions: how the dentate gyrus, CA3, and CA1 process spatial information. Behav. Neurosci. 122, 16-26.

Guzowski, J. F., Knierim, J. J., and Moser, E. I. (2004). Ensemble dynamics of hippocampal regions CA3 and CA1. Neuron 44, 581-584.

Hagena, H., and Manahan-Vaughan, D. (2010). Frequency facilitation at mossy fiber-CA3 synapses of freely behaving rats contributes to the induction of persistent LTD via an adenosine-A1 receptor-regulated mechanism. Cereb. Cortex 20, 1121-1130.

Hagena, H., and Manahan-Vaughan, D. (2011). Learning-facilitated synaptic plasticity at CA3 mossy fiber and commissural-associational synapses reveals different roles in information processing. Cereb. Cortex 21, 2442-2449.

Hagena, H., and Manahan-Vaughan, D. (2012). Learning-facilitated long-term depression and longterm potentiation at mossy fiber-CA3 synapses requires activation of $\beta$-adrenergic receptors. Front. Integr. Neurosci. 6:23. doi: 10.3389/fnint.2012.00023

Harris, E. W., and Cotman, C. W. (1986). Long-term potentiation of guinea pig mossy fiber responses is not blocked by N-methyl D-aspartate antagonists. Neurosci. Lett. 70, 132-137.

Hicks, A., Davis, S., Rodger, J., Helme-Guizon, A., Laroche, S., and Mallet, J. (1997). Synapsin I and syntaxin 1B: key elements in the control of neurotransmitter release are regulated by neuronal activation and long-term potentiation in vivo. Neuroscience 79 , 329-340.

Hjorth-Simonsen, A. (1973). Some intrinsic connections of the hippocampus in the rat: an experimental analysis. J. Comp. Neurol. 147, 145-161.

Hong, S.-S., Qian, H., Zhao, P., BazzyAsaad, A., and Xia, Y. (2007). Anisomycin protects cortical neurons from prolonged hypoxia with differential regulation of p38 and ERK. Brain Res. 1149, 76-86.

Huang, Y. Y., and Kandel, E. R. (1994). Recruitment of long-lasting and protein kinase A-dependent longterm potentiation in the CAl region of hippocampus requires repeated tetanization. Learn. Mem. 1, 74-82.

Huang, Y. Y., Li, X. C., and Kandel, E. R. (1994). cAMP contributes to mossy fiber LTP by initiating both a covalently mediated early phase and macromolecular synthesis-dependent late phase. Cell 79, 69-79.

Huber, K. M., Kayser, M. S., and Bear, M. F. (2000). Role for rapid dendritic protein synthesis in hippocampal mGluR-dependent long-term depression. Science 288, 1254-1257.

Ishizuka, N., Weber, J., and Amaral, D. G. (1990). Organization of intrahippocampal projections originating from CA3 pyramidal cells in the rat. J. Comp. Neurol. 295, 580-623.

Job, C., and Eberwine, J. (2001). Localization and translation of mRNA in dendrites and axons. Nat. Rev. Neurosci. 2, 889-898.

Kamiya, H., Shinozaki, H., and Yamamoto, C. (1996). Activation of metabotropic glutamate receptor type 2/3 suppresses transmission at rat hippocampal mossy fibre synapses. J. Physiol. 493( $\mathrm{Pt} 2)$, 447-455.

Kandel, E. R. (2001). The molecular biology of memory storage: a dialogue between genes and synapses. Science 294, 1030-1038. 
Kemp, A., and Manahan-Vaughan, D. (2007). Hippocampal long-term depression: master or minion in declarative memory processes? Trends Neurosci. 30, 111-118.

Kemp, A., and Manahan-Vaughan, D. (2008). The hippocampal CA1 region and dentate gyrus differentiate between environmental and spatial feature encoding through long-term depression. Cereb. Cortex $18,968-977$.

Kesner, R. P. (2007). Behavioral functions of the CA3 subregion of the hippocampus. Learn. Mem. 14, 771-781.

Kesner, R. P., and Hopkins, R. O. (2006). Mnemonic functions of the hippocampus: a comparison between animals and humans. Biol. psychol. 73, 3-18.

Kesner, R. P., and Warthen, D. K. (2010). Implications of CA3 NMDA and opiate receptors for spatial pattern completion in rats. Hippocampus 20, 550-557.

Klausnitzer, J., and Manahan-Vaughan, D. (2008). Frequency facilitation at mossy fiber-CA3 synapses of freely behaving rats is regulated by adenosine Al receptors. J. Neurosci. 28, 4836-4840.

Kobayashi, K., Manabe, T., and Takahashi, T. (1996). Presynaptic long-term depression at the hippocampal mossy fiber-CA3 synapse. Science 273, 648-650.

Krug, M., Lössner, B., and Ott, T. (1984). Anisomycin blocks the late phase of long-term potentiation in the dentate gyrus of freely moving rats. Brain Res. Bull. 13, 39-42.

Kumaran, D., and Maguire, E. A. (2007). Match mismatch processes underlie human hippocampal responses to associative novelty. J. Neurosci. 27, 8517-8524.

Lanahan, A., and Worley, P. (1998). Immediate-early genes and synaptic function. Neurobiol. Learn. Mem. $70,37-43$.

Laurberg, S. (1979). Commissural and intrinsic connections of the rat hippocampus. J. Comp. Neurol. 184, 685-708.

Lee, I., Rao, G., and Knierim, J. J. (2004). A double dissociation between hippocampal subfields: differential time course of CA3 and CAl place cells for processing changed environments. Neuron 42 , 803-815.

Leutgeb, S., Leutgeb, J. K., Treves, A., Moser, M.-B., and Moser, E. I. (2004). Distinct ensemble codes in hippocampal areas CA3 and CA1. Science 305, 1295-1298.

Li, Q., Rothkegel, M., Xiao, Z. C., Abraham, W. C., Korte, M., and
Sajikumar, S. (2012). Making synapses strong: metaplasticity prolongs associativity of long-term memory by switching synaptic tag mechanisms. Cereb. Cortex. doi: 10.1093/cercor/bhs315. [Epub ahead of print].

Lisman, J. E., and Grace, A. A. (2005). The hippocampal-VTA loop: controlling the entry of information into long-term memory. Neuron 46 703-713.

Lonart, G. (2002). RIM1: an edge for presynaptic plasticity. Trends Neurosci. 25, 329-332.

Lynch, M. A., Voss, K. L., Rodriguez, J., and Bliss, T. V. (1994). Increase in synaptic vesicle proteins accompanies long-term potentiation in the dentate gyrus. Neuroscience 60, 1-5.

Manahan-Vaughan, D. (1997). Group 1 and 2 metabotropic glutamate receptors play differential roles in hippocampal long-term depression and long-term potentiation in freely moving rats. J. Neurosci. 17, 3303-3311.

Manahan-Vaughan, D., Behnisch, G., Vieweg, S., Reymann, K. G., and Behnisch, T. (1998). Semi-automated analysis of NMDA-mediated toxicity in digitised colour images from rat hippocampus. J. Neurosci. Methods 82, 85-95.

Manahan-Vaughan, D., Kulla, A., and Frey, J. U. (2000). Requirement of translation but not transcription for the maintenance of long-term depression in the $\mathrm{CAl}$ region of freely moving rats. J. Neurosci. 20 , 8572-8576.

Marr, D. (1971). Simple memory: a theory for archicortex. Philos. Trans. R. Soc. Lond. B Biol. Sci. 262, 23-81.

Martin, K. C., Casadio, A., Zhu, H., Yaping, E., Rose, J. C., Chen, M., et al. (1997). Synapse-specific, longterm facilitation of aplysia sensory to motor synapses: a function for local protein synthesis in memory storage. Cell 91, 927-938.

Matthies, H., Frey, U., Reymann, K., Krug, M., Jork, R., and Schröeder, H. (1990). Different mechanisms and multiple stages of LTP. Adv. Exp. Med. Biol. 268, 359-368.

McNaughton, B., and Morris, R. (1987). Hippocampal synaptic enhancement and information storage within a distributed memory system. Trends Neurosci. 10, 408-415.

Messaoudi, E., Ying, S.-W., Kanhema, T., Croll, S. D., and Bramham, C. R. (2002). Brain-derived neurotrophic factor triggers transcriptiondependent, late phase long-term potentiation in vivo. J. Neurosci. 22 , 7453-7461.

Moore, K. A., Nicoll, R. A., and Schmitz, D. (2003). Adenosine gates synaptic plasticity at hippocampal mossy fiber synapses. Proc. Natl. Acad. Sci. U.S.A. 100, 14397-14402.

Morimoto, K., Sato, K., Sato, S., Yamada, N., and Hayabara, T. (1998). Time-dependent changes in rat hippocampal synapsin I mRNA expression during longterm potentiation. Brain Res. 783 , 57-62.

Morrell, F. (1991). Kindling and Synaptic Plasticity. Boston, MA: Taylor and Francis.

Nakazawa, K. (2002). Requirement for hippocampal CA3 NMDA receptors in associative memory recall. Science 297, 211-218.

Nguyen, P. V., Abel, T., and Kandel, E. R. (1994). Requirement of a critical period of transcription for induction of a late phase of LTP. Science 265, 1104-1107.

Nguyen, P. V., and Kandel, E. R. (1996). A macromolecular synthesisdependent late phase of long-term potentiation requiring cAMP in the medial perforant pathway of rat hippocampal slices. J. Neurosci. 16, 3189-3198.

Nikitin, V. P., and Kozyrev, S. A. (2005) Long-term synaptic facilitation in defensive behavior command neurons in the snail during acquisition of sensitization depends on RNA synthesis. Neurosci. Behav. Physiol. $35,355-362$.

O'Reilly, R. C., and McClelland, J. L. (1994). Hippocampal conjunctive encoding, storage, and recall: avoiding a trade-off. Hippocampus 4, 661-682.

Osten, P., Valsamis, L., Harris, A., and Sacktor, T. C. (1996). Protein synthesis-dependent formation of protein kinase Mzeta in longterm potentiation. J. Neurosci. 16 2444-2451.

Otani, S., and Abraham, W. C. (1989). Inhibition of protein synthesis in the dentate gyrus, but not the entorhinal cortex, blocks maintenance of long-term potentiation in rats. Neurosci. Lett. 106 , 175-180.

Otani, S., Marshall, C. J., Tate, W. P. Goddard, G. V., and Abraham, W. C. (1989). Maintenance of long-term potentiation in rat dentate gyrus requires protein synthesis but not messenger RNA synthesis immediately post-tetanization. Neuroscience 28, 519-526.

Ouyang, Y., Rosenstein, A., Kreiman, G., Schuman, E. M., and Kennedy,
M. B. (1999). Tetanic stimulation leads to increased accumulation of $\mathrm{Ca}(2+) /$ calmodulin-dependent protein kinase II via dendritic protein synthesis in hippocampal neurons. J. Neurosci. 19, 7823-7833.

Paxinos, G., and Watson, C. (1986). The Rat Brain in Stereotaxic Coordinates. San Diego, CA: Academic Press.

Pevzner, A., Miyashita, T., Schiffman, A. J., and Guzowski, J. F. (2012). Temporal dynamics of Arc gene induction in hippocampus: relationship to context memory formation. Neurobiol. Learn. Mem. 97, 313-320.

Pöschel, B., and Manahan-Vaughan, D. (2007). Persistent ( $>24 \mathrm{~h}$ ) longterm depression in the dentate gyrus of freely moving rats is not dependent on activation of NMDA receptors, L-type voltagegated calcium channels or protein synthesis. Neuropharmacology 52, 46-54.

Rolls, E. T., and Kesner, R. P. (2006). A computational theory of hippocampal function, and empirical tests of the theory. Prog. Neurobiol. 79, $1-48$

Sadile, A. G., Neugebauer, A., Gessi, T., Marchionni, S., and Giuditta, A. (1995). Brain RNA synthesis, longterm potentiation and depression at the perforant path-granule cell synapse in the guinea pig. Brain Res. Bull. 36, 515-526.

Saha, R. N., Wissink, E. M., Bailey, E. R., Zhao, M., Fargo, D. C., Hwang, J.-Y., et al. (2011). Rapid activityinduced transcription of Arc and other IEGs relies on poised RNA polymerase II. Nat. Neurosci. 14, 848-856.

Sajikumar, S., and Frey, J. U. (2004). Late-associativity, synaptic tagging, and the role of dopamine during LTP and LTD. Neurobiol. Learn. Mem. 82, 12-25.

Sajikumar, S., and Korte, M. (2011). Metaplasticity governs compartmentalization of synaptic tagging and capture through brain-derived neurotrophic factor (BDNF) and protein kinase Mzeta (PKMzeta). Proc. Natl. Acad. Sci. U.S.A. 108, 2551-2556.

Sajikumar, S., Navakkode, S., and Frey, J. U. (2007). Identification of compartment- and process-specific molecules required for "synaptic tagging" during long-term potentiation and long-term depression in hippocampal CA1. J. Neurosci. 27, 5068-5080.

Salin, P. A., Scanziani, M., Malenka, R. C., and Nicoll, R. A. (1996). Distinct short-term plasticity at two 
excitatory synapses in the hippocampus. Proc. Natl. Acad. Sci. U.S.A. 93, 13304-13309.

Smith, W. B., Aakalu, G., and Schuman, E. M. (2001). Local protein synthesis in neurons. Curr. Biol. 11, R901-R903.

Stanton, P. K., and Sarvey, J. M. (1984). Blockade of long-term potentiation in rat hippocampal CA1 region by inhibitors of protein synthesis. J. Neurosci. 4, 3080-3088.

Staubli, U., Larson, J., and Lynch, G. (1990). Mossy fiber potentiation and long-term potentiation involve different expression mechanisms. Synapse 5, 333-335.

Steward, O., and Schuman, E. M. (2001). Protein synthesis at synaptic sites on dendrites. Annu. Rev. Neurosci. 24, 299-325.

Steward, O., and Worley, P. (2001). Localization of mRNAs at synaptic sites on dendrites. Results Probl. Cell. Differ. 34, 1-26.

Sutton, M. A., and Schuman, E. M. (2006). Dendritic protein synthesis, synaptic plasticity, and memory. Cell 127, 49-58.
Swanson, L. W., Wyss, J. M., and Cowan, W. M. (1978). An autoradiographic study of the organization of intrahippocampal association pathways in the rat. J. Comp. Neurol. 181, 681-715.

Toth, K., Suares, G., Lawrence, J. J., Philips-Tansey, E., and McBain, C. J. (2000). Differential mechanisms of transmission at three types of mossy fiber synapse. J. Neurosci. 20, 8279-8289.

Treves, A., and Rolls, E. T. (1992). Computational constraints suggest the need for two distinct input systems to the hippocampal CA3 network. Hippocampus 2, 189-199.

Treves, A., and Rolls, E. T. (1994). Computational analysis of the role of the hippocampus in memory. Hippocampus 4, 374-391.

Tzounopoulos, T., Janz, R., Südhof, T. C., Nicoll, R. A., and Malenka, R. C. (1998). A role for cAMP in long-term depression at hippocampal mossy fiber synapses. Neuron 21 , 837-845.

Vanderklish, P. W., and Edelman, G. M. (2002). Dendritic spines elongate after stimulation of group 1 metabotropic glutamate receptors in cultured hippocampal neurons. Proc. Natl. Acad. Sci. U.S.A. 99 1639-1644.

Vinogradova, O. S. (2001). Hippocampus as comparator: role of the two input and two output systems of the hippocampus in selection and registration of information. Hippocampus 11 , 578-598.

Weisskopf, M. G., and Nicoll, R. A (1995). Presynaptic changes during mossy fibre LTP revealed by NMDA receptor-mediated synaptic responses. Nature 376, 256-259.

Xiang, Z., Greenwood, A. C. Kairiss, E. W., and Brown, T. H. (1994). Quantal mechanism of long-term potentiation in hippocampal mossy-fiber synapses. J. Neurophysiol. 71, 2552-2556.

Yeckel, M. F., Kapur, A., and Johnston, D. (1999). Multiple forms of LTP in hippocampal CA3 neurons use a common postsynaptic mechanism. Nat. Neurosci. 2, 625-633.

Zalutsky, R. A., and Nicoll, R. A. (1990). Comparison of two forms of long-term potentiation in single hippocampal neurons. Science 248, 1619-1624.

Conflict of Interest Statement: The authors declare that the research was conducted in the absence of any commercial or financial relationships that could be construed as a potential conflict of interest.

Received: 27 November 2012; accepted: 12 February 2013; published online: 01 March 2013.

Citation: Hagena $H$ and ManahanVaughan D (2013) Differentiation in the protein synthesis-dependency of persistent synaptic plasticity in mossy fiber and associational/commissural CA3 synapses in vivo. Front. Integr. Neurosci. 7:10. doi: 10.3389/fnint.2013.00010

Copyright (c) 2013 Hagena and Manahan-Vaughan. This is an openaccess article distributed under the terms of the Creative Commons Attribution License, which permits use, distribution and reproduction in other forums, provided the original authors and source are credited and subject to any copyright notices concerning any third-party graphics etc. 